\title{
Independência do Banco Central: uma crítica sob a perspectiva pós-keynesiana de seus pressupostos e objetivos
}

\author{
Raphael Guilherme Araujo Torrezan ${ }^{1}$ \\ Guilherme da Silva² \\ Danielle de Almeida Mota Soares ${ }^{3}$ \\ Eduardo Strachman ${ }^{4}$
}

\begin{abstract}
Resumo: Este trabalho analisa a tese da Independência do Banco Central sob uma perspectiva pós-keynesiana, contrastando-a com os pressupostos da teoria novo-clássica e de outras abordagens ortodoxas, encarando o Banco Central como uma autoridade que detém funções que vão além da estabilização de preços. Para isso, foram analisadas as bases teóricas das propostas de independência e da eficiência da política monetária, como estimuladoras da economia. Posteriormente, mostrou-se a crítica pós-keynesiana a essa abordagem, ressaltando os argumentos contrários à neutralidade da moeda e à taxa natural de desemprego, demonstrando a irrealidade e fragilidade desses pressupostos, além de sua incompatibilidade com regimes democráticos, propondo uma atuação conjunta do Banco Central e de outros instrumentos macroeconômicos.
\end{abstract}

Palavras-chave: Banco Central; Independência; Política Monetária Pós-Keynesiana

Classificação JEL: E52; E58; E12

Central Bank Independence: a Post-Keynesian Critic of its Assumptions and Goals

\begin{abstract}
This article aims to discuss the Central Bank's Independence under a post-Keynesian perspective. The article sets out arguments in favor of running an independent monetary authority, which would have the purpose of pursuing monetary stability. However, the post-Keynesian theory disagrees with the assumptions, which anchored the IBC's thesis, as the neutrality of money and the natural rate of unemployment, which show no correspondence to reality. The article assumes that the Central Bank is an important part of the functioning of the economy and may lead to development mainly when there is a joint action of the Central Bank and other macroeconomic agents and instruments.
\end{abstract}

1 Economista e Mestrando em Economia na Universidade Estadual Paulista "Júlio de Mesquita Filho"- UNESP de Araraquara. E-mail: raphatorrezan@hotmail.com

2 Economista formado pela Unicamp e Mestrando em Economia na Universidade Estadual Paulista "Júlio de Mesquita Filho"- UNESP de Araraquara. E-mail: guilhermedasilva09@gmail.com

3 Economista e Mestranda em Economia na Universidade Estadual Paulista "Júlio de Mesquita Filho"- UNESP de Araraquara. E-mail: danielle_mota@hotmail.com

4 Livre-Docente do Depto. de Economia na Universidade Estadual Paulista "Júlio de Mesquita Filho" - UNESP de Araraquara e Pesquisador do Conselho Nacional de Desenvolvimento Científico e Tecnológico (CNPq).E-mail: edstrach@fclar.unesp.br 
Key-words: Central Bank; Independence; Post-Keynesian Monetary Policy.

JEL Classification: E52; E58; E12

\section{Introdução}

De tempos em tempos, o debate em relação à independência do Banco Central (IBC) volta à tona. Uma parcela dos economistas defende que a presença de um Banco Central Independente é a solução para vários problemas econômicos e que conduziria a um cenário macroeconômico harmonioso, enquanto outros autores criticam fortemente essas suposições.

A tese de IBC ganhou força ao longo da década de 1970, quando ocorre a ascensão da escola de pensamento novo-clássica. O descompasso entre as ações da política monetária e o aumento generalizado dos preços, que afetava os países industrializados, estimulou a produção acadêmica sobre o assunto. $\mathrm{O}$ trabalho de Kydland e Prescott (1977) foi crucial para o início do debate, ao argumentar sobre a baixa compatibilidade dos policy makers para conduzir políticas monetárias e as pressões políticas que esses sofreriam em busca de resultados no curto prazo.

A solução para esse impasse residiria na independência do Banco Central que, assim, ao passar a atuar de forma alheia a questões políticas, ganharia maior eficiência no uso de seus vários instrumentos, a fim de atingir seus objetivos. Porém, a independência do Banco Central não deve ser confundida com sua autonomia. Enquanto no primeiro caso existe liberdade quanto a seus objetivos e à maneira como usa seus instrumentos, no segundo caso a Autoridade Monetária possui autonomia para utilizar os instrumentos, mas não a independência quanto aos objetivos. Dessa forma, o Banco Central autônomo, mas não independente, poderia continuar atrelado à decisões políticas em vigor, sendo seu papel operacionalizá-las da melhor maneira possível (CROCCO; JAYME, 2003, p. 12).

Este trabalho analisa a tese do IBC sob uma perspectiva pós-keynesiana, contrastando-a com os pressupostos da teoria novo-clássica e de outras abordagens ortodoxas, isto é, encarando o $\mathrm{BC}$ como uma autoridade que detém funções que vão além da estabilização de preços. Para isso, divide-se em três seções, além dessa introdução e da conclusão. A primeira aborda a explicação quanto à eficiência da política monetária, na teoria novo-clássica, com o propósito de melhor compreender as razões, pressupostos e determinantes por trás de sua defesa da independência do Banco Central. A segunda apresenta a tese do BCI e a consolidação dessa teoria ao longo dos anos, inclusive para além das fronteiras novo-clássicas, destacando os diversos tratamentos sobre o assunto, que emergiram com o transcorrer do tempo.

A seção três divide-se em duas subseções: a primeira mostra o papel da política monetária em Keynes e a razão de essa não ser considerada ineficiente; e a 
segunda analisa a IBC criticamente por intermédio de autores pós-keynesianos, detalhando como essa ideia pode ser encarada como verdadeiro entrave para uma condução econômica mais eficaz. Por fim, na última seção, algumas breves conclusões são apresentadas.

\section{A ineficiência da política monetária na escola novo-clássica: alicer- ces para a tese do BCI}

A premissa de um Banco Central independente tem origem na escola novo-clássica, a qual adicionou novos pressupostos comportamentais à base da teoria monetarista. Para os novo-clássicos, agentes tomam decisões com base não apenas no passado, mas também em expectativas futuras, muitas vezes tornando as intervenções macroeconômicas ineficazes para a solução de problemas econômicos.

A escola novo-clássica critica, assim, regularmente a formulação de teorias apoiadas em alicerces keynesianos, as quais seriam muito otimistas ao descrever a capacidade de o Estado intervir de forma favorável na economia. Ademais, para os monetaristas e seus seguidores mais radicais, os novo-clássicos, a corrente keynesiana seria quase exclusivamente útil para a explicação de recessões e depressões econômicas (VERCELLI, 1991, p.132; BULLIO; RAIMUNDO, 2008. p. 5).

Como Carvalho et al. (2007, p. 126) mostram, a teoria novo-clássica parte do pressuposto da existência de várias "taxas naturais", ancoradas sob a perspectiva da racionalidade dos agentes. Dentre essas "taxas naturais", encontra-se a taxa natural de desemprego. Quando alguma taxa corrente se iguala à sua taxa natural, a economia repousa em equilíbrio, a menos no tocante a essa variável específica. Por outro lado, políticas econômicas descuidadas e voluntaristas gerariam ruídos e deslocamentos com relação a essas taxas ótimas, de equilíbrio. Carvalho et al. (2007, p.126) explicitam a inoperância das políticas monetárias pela corrente novo-clássica com base na função de oferta de Lucas.

$$
U_{t}=U_{n}-\alpha\left(\pi_{t}-\pi_{t}^{e}\right) \quad \alpha>0
$$

Sendo $\left.\left(U_{t}\right)\right)$ a taxa corrente de desemprego, $\left(U_{n}\right)$ a taxa natural de desemprego, $\left.\left(\pi_{t}\right)\right)$ a inflação no período $t,\left(\pi_{t}^{\theta}\right)$ a inflação esperada no período $t$ e $\alpha$ consiste em um parâmetro positivo.

Baseando-se nessa equação, a taxa corrente de desemprego se manterá igual à taxa natural quando confirmadas as expectativas da inflação. No entanto, a hipótese novo-clássica adiciona a noção de expectativa racional dos agentes, que pode ser explicitada da seguinte maneira (MODENESI, 2005, p.142):

$$
\pi_{t}^{e}=E\left(\frac{\pi_{t}}{l_{t-1}}\right)
$$


Essa equação aponta que a expectativa da inflação no período é dada pela esperança matemática da inflação presente, ponderada pelas informações que os agentes possuem quanto à inflação até o período imediatamente anterior. É importante frisar que a inflação observada dependerá do estoque de moeda $\left(M_{T}\right)$ e de choques não previstos na demanda $\left(d_{t}\right)$. Sendo assim:

$$
\pi_{t}=M_{t}+d_{t}
$$

Logo, as expectativas de inflação relacionam-se com as expectativas de variação do estoque monetário:

$$
\pi_{t}^{e}=M_{t}^{e}
$$

Em que $M$ é variação do estoque monetário esperado.

Em Carvalho et al. (2007, p. 128), as equações 2, 3 e 4 apontam que os agentes teriam completo conhecimento sobre as variações do estoque monetário e, portanto, supondo que $\mathrm{d}=0$, não haveria frustrações dessas expectativas racionais.

Ao substituir as equações 3 e 4 na função 1, chegamos a:

$$
U_{t}=U_{n}-\alpha\left(M_{t}-M_{t}^{e}\right)
$$

Assim, se a taxa corrente de desemprego for igual à taxa natural, a presença de uma política monetária expansiva não conduziria a um aumento do emprego, mas sim a um aumento no nível geral de preços, proporcional ao aumento do estoque de moeda. Logo, qualquer ação dos policy makers visando ao uso de política monetária para afetar as variáveis reais da economia não se traduziria em alterações nos níveis de produto, renda e emprego, mas sim de preços.

Apesar dessas limitações da política monetária, para Sargent e Wallace (1975, p. 247), a política monetária implica algum efeito real sobre as variáveis econômicas, se for executada de forma que surpreenda os agentes. Portanto, apenas a presença de variações na quantidade de moeda oriundas de uma política monetária inesperada teria efeitos não neutros sobre variáveis reais (MODENESI, 2005, p.154). A função abaixo mostra como se daria o impacto da política monetária de surpresa sobre essas variáveis.

$$
M_{t}=\delta\left(U_{t-1}-U_{n}\right)+(\varnothing)
$$

Na equação acima, $\delta$ é um parâmetro positivo e $\emptyset$ é a variável correspondente aos rumos da política monetária da qual apenas os policy makers detêm as informações relevantes ex-ante. Nesse caso, portanto, os agentes, que na teoria novo- 
-clássica são racionais, formariam suas expectativas acerca do estoque monetário de acordo com:

$$
M_{t}^{e}=\delta\left(U_{t-1}-U_{n}\right)
$$

Por meio de um rearranjo entre as funções tem-se:

$$
U_{t}=U_{n}-\alpha(\emptyset)
$$

A taxa corrente de desemprego será diferente da taxa natural quando ocorrer o uso da variável $(\emptyset)$, que causará surpresa aos agentes, alterando suas expectativas, em razão da inesperada mudança no estoque monetário, a qual terá impacto sobre a diferença entre a taxa corrente e a taxa natural de desemprego. Logo, qualquer alteração na economia oriunda da variação dos estoques monetários decorre de erros na expectativa dos agentes - por exemplo, os empresários interpretariam de maneira equivocada o aumento de preços e demandariam maior mão-de-obra no período. No entanto, gradualmente os agentes assimilariam que esse aumento no preço relativo dos produtos foi ocasionado por um aumento na oferta de moeda, não por outras razões, e a taxa corrente de desemprego retornaria a seu nível natural.

Esse cenário, consequentemente, corroboraria a tese da escola novo-clássica de que os policy makers devem apenas se ater a proporcionar um ambiente de baixa inflação, pois o uso de políticas monetárias para outros fins apenas conduziria a ambientes de incerteza e desconfiança em relação à autoridade monetária, além de não representar qualquer efeito a longo prazo. Dessa maneira, caberia às autoridades criar um ambiente de confiança e previsibilidade para o funcionamento do mercado, sem gerar um cenário inflacionário, de acordo com expectativas incertas de aumento na oferta monetária.

Kydland e Prescott (1977, p. 486) endossam essa crença na inoperância da política monetária discricionária, por meio da teoria da inconsistência temporal, que argumenta que o principal pilar para a estabilidade de uma economia e, portanto, para seu melhor desempenho, é a adoção de regras claras e rígidas na condução das políticas macroeconômicas.

O raciocínio advém, mais uma vez, dessa mesma hipótese quanto à racionalidade dos agentes, na qual esses considerariam as informações passadas e os dados presentes para realizar projeções, usualmente corretas, acerca do futuro. Logo, as políticas discricionárias não se traduziriam em eficiência e em ganhos de bem-estar, mas passariam, quando muito, a atrapalhar o julgamento ótimo dos agentes racionais, nos seus vários momentos de decisão (CARVALHO et al., 2007, p. 130).

Em suma, o governo pode anunciar determinada política monetária, que julga adequada para a solução de problemas, no instante $t$, mas elas somente serão implantadas no momento $t+1$. Neste ínterim, entre o instante $t \mathrm{e} t+1$, os agentes privados 
tomarão suas decisões apoiados naquilo que for anunciado em (ou esperado quanto à) $t$. Logo, no instante em que a política monetária entrar em vigor $(t+1)$, ela já se encontrará inadequada, pois os agentes terão adaptado suas expectativas, tornando a política ineficaz antes mesmo de entrar em vigor. Levando isso em consideração, a autoridade monetária consciente deve reavaliar seus planos e sua capacidade de intervenção (MODENESI, 2005, p. 154).

Para Barro e Gordon (1983), caso essa revisão não ocorra e a autoridade monetária insista em intervir de maneira voluntarista, isso acarretaria um viés inflacionário, com resultados positivos ínfimos, ademais, de temporários, mas resultando em um aumento duradouro da inflação. Adicionalmente, na presença de um anúncio de uma política monetária expansiva, os salários teriam um reajuste maior pela antecipação da elevação de preços por parte dos trabalhadores, enquanto, é claro, frente a uma redução monetária, os salários diminuiriam, também em razão de efeitos das expectativas sobre a atuação desses mesmos trabalhadores. Por outro lado, se os agentes privados perdessem sua confiança nas ações da autoridade monetária, o reajuste se daria de forma inadequada, não resultando em qualquer efeito favorável nem mesmo no curto prazo.

Desta maneira a solução mais eficiente seria a adoção de regras claras, que amenizariam as perdas dos vários agentes, tornando o problema da inconsistência temporal pequeno o suficiente, ou mesmo inexistente, contribuindo para a credibilidade do governo na condução da política monetária (KYDLAND; PRESCOTT, 1977, p. 487; MENDONÇA, 2001, p. 181).

\section{A tese do Banco Central independente}

A independência do Banco Central é vista como uma grande contribuição do mainstream para o problema da política monetária ineficiente em longo prazo e o consequente ônus inflacionário, já que transmitiria confiança aos agentes privados sobre a determinação de a política econômica não estar focada nas resoluções de problemas políticos no curto prazo, mas sim em conter a inflação.

Freitas (2006, p. 273) destaca que, segundo a teoria dos political business cycles, os políticos tenderiam a criar condições econômicas que poderiam gerar vantagens no processo eleitoral, mesmo que essas manobras implicassem em ciclos econômicos sub ótimos. O Banco Central, subordinado ao governo vigente, estaria fadado a realizar ações condicionadas a ganhos apenas de curto prazo, limitadas inconsistentemente a esse horizonte temporal finito. O resultado dessas escolhas populistas, somadas a informações assimétricas dos agentes privados, só reiteraria o viés inflacionário desse organismo, sob tal institucionalidade.

Assim, o governo deveria ter como meta a criação de um arranjo institucional que evitasse inconsistências dessa natureza. Dentro desse arranjo, pode ser destacada a criação e manutenção de um Banco Central independente, com um caráter estritamente apolítico e focado exclusivamente na estabilização e manutenção dos 
níveis de preços. Ademais, esse arranjo independente deveria ser gerido por técnicos com um horizonte temporal maior, alheios a questões conjunturais, conduzindo a política monetária sem interferências externas. Para atingir esse objetivo, o BC teria independência até mesmo para contrariar e frustrar outros objetivos do governo. Cabe ressaltar que essa entidade seria avaliada por agências também independentes e indiferentes ao poder discricionário dos governos, as quais acompanhariam o desempenho da política monetária (ALESINA, SUMMERS, 1993, p. 152).

Como Carvalho et al. (2007, p.133) demonstram, a tese da independência do Banco Central pauta-se em torno do trinômio credibilidade-reputação-delegação. Credibilidade e reputação consistem em fatores importantes para a manutenção da confiança dos agentes em relação às políticas adotadas pelo $\mathrm{BC}$ e, para os defensores da independência dos Bancos Centrais, a ausência de políticas discricionárias aumentaria a credibilidade da Autoridade Monetária. E a reputação de um Banco Central com um histórico não discricionário manteria as expectativas dos agentes em um nível estável, levando a taxa corrente de desemprego a manter-se no mesmo patamar que a taxa natural.

Mendonça (2001, p. 28) avaliou as teorias que contemplavam a tese do IBC, sintetizando-as em três gerações distintas. A primeira tem origem no trabalho de Rogoff (1985), sustentando que o comando do Banco Central deve ser delegado a um central banker cujas preferências sejam mais avessas à inflação do que a média da sociedade. Dessa maneira, seria possível sustentar uma baixa variação do nível de preços, pois os agentes presentes determinariam suas expectativas inflacionárias de acordo com a observação do comportamento desse central banker. Mendonça (2001, p. 29) aponta que essa teoria não leva a um ótimo bem-estar e que a sustentação de um baixo viés inflacionário ocorre por meio de menor estabilização e maior comprometimento do nível de produto. Também destaca que, nesse caso, não há trade-off entre compromisso do central banker e flexibilidade, o que não é eficiente para solucionar o problema da inconsistência temporal.

Outra abordagem acerca da independência do Banco Central está na teoria de Walsh (1995), um referencial para o que é considerada segunda geração de teorias sobre o IBC, a qual propõe a formulação de algo como um contrato entre o BC e o governo. Esse modelo assume que o conservadorismo do central banker não resolverá os problemas inflacionários, mas sim a formulação de contratos claros e rígidos, que onerem o BC caso a inflação não atinja o nível esperado. Nesse caso, os custos que recaem sobre o Banco Central podem ser tanto a demissão de funcionários quanto cortes financeiros à instituição. Questões importantes que envolvem esses modelos são a precariedade das técnicas para conduzir a inflação à meta desejada e os riscos inerentes à falta de controle democrático sobre o IBC (MENDONÇA, 2001, p. 33).

A terceira geração de modelos de IBC baseia-se principalmente no trabalho de Svensson (1997), que tenta conciliar os modelos oriundos das gerações anteriores, propondo a delegação do comando do $\mathrm{BC}$ a um agente avesso à inflação, com o uso de metas de inflação claras, as quais, caso não cumpridas, também acarretariam em ônus 
aos gestores do BC. Dessa forma, seriam reduzidos o viés inflacionário e a inconsistência temporal, dado que os agentes teriam expectativas de uma baixa variação dos níveis de preços, também por conta de diretrizes que apontam para a manutenção da inflação dentro de metas pré-estabelecidas. Porém, também nesses modelos emergem questões como as vantagens de não delegação de metas e instrumentos a um IBC, quando há incerteza quanto às preferências da instituição ou de seu(s) dirigente(s) principal(is) no que tange à inflação, crescimento e trade-off entre esses. Isso pode ser tratado como um caso de relação agente (IBC)-principal (população ou eleitorado) simples ou como um caso de dois níveis: agente 2 (IBC)-principal 2 (governo), com base em agente 1 (população ou eleitorado)-principal 1 (governo).

Estudos empíricos surgiram para compreender o real impacto da independência dos Bancos Centrais sobre suas respectivas economias. Cukierman, Webb e Neyapti (1992, p. 362) apontam que países como Nova Zelândia, Canadá, Suécia, Reino Unido, dentre outros, que formularam arranjos institucionais para dar suporte à independência do Banco Central, obtiveram taxas de inflação menores do que esperado. Para mensurar o grau de autonomia das autoridades monetárias, esses autores desenvolveram um índice que considerava os seguintes critérios:

(i) grau de rotatividade dos dirigentes: quanto maior a estabilidade dos dirigentes, maior a independência do Banco Central;

(ii) estatutos dos $\mathrm{BC}^{\prime}$ 's;

(iii) questionários sobre as metas do $\mathrm{BC}$ e sua relação com o governo, enviados para especialistas de cada país.

A primeira e a segunda características possuem um peso menor na construção dos índices, pois ambas podiam estar sujeitas a interferências do governo. Por exemplo, um central banker há muito tempo no comando do BC poderia estar alinhado aos interesses políticos, o que lhe traria comodidade no cargo. Já o estatuto pode conter falhas, muitas vezes imperceptíveis, aos olhos dos agentes privados. Logo, são os questionários direcionados a especialistas que trariam maior segurança na construção dos indicadores (MENDONÇA, 2001, p. 45).

As análises oriundas desse índice de Cukierman, Webb e Neyapti (1992), aplicado em aproximadamente 70 países, com diversos graus de desenvolvimento econômico, corroboraria a hipótese de eficiência obtida por meio de arranjos institucionais que permitissem a atuação dos BCI's. Logo, tal argumento tornou-se basilar para os defensores de políticas monetárias não discricionárias, com atuação mínima da Autoridade Monetária.

Mendonça (2001, p. 44) sumariza algumas conclusões oriundas de alguns testes empíricos, explicando que: (i) em economias industriais há uma correlação negativa entre independência do Banco Central e inflação; (ii) porém, em países menos desenvolvidos não há relação entre a presença de um BCI e a inflação; (iii) metas de inflação podem ser fatores importantes para a redução da inflação, mas há uma correlação muito mais forte entre essas duas variáveis para países desenvolvidos e que já se encontravam com baixa inflação previamente à adoção de metas, essa 
correlação é bem mais frágil no caso dos países em desenvolvimento; e (iv) BCI’s não são financiadores do déficit dos países.

Soma-se a isso uma série de estudos empíricos que parecem reforçar a tese de que os BCI's são detentores da solução para problemas inflacionários. Os testes aplicados com base nos índices, como o de Cukiermann, tendem a corroborar a hipótese de que políticas monetárias discricionárias não geram resultados eficientes, apenas temporários (MENDONÇA, 2004, p. 349). É claro que estudos empíricos ou mesmo compilações desses estudos estão sujeitos a críticas e correções, já que sempre existem estudos que apontam em direções contrárias. Nesse sentido, após a crise internacional que se inicia em setembro de 2008, alguns autores pedem uma completa revisão ou abandono dos modelos de metas de inflação, por engessarem excessivamente as possibilidades de atuação em crises econômicas e financeiras e também por se basearem mais em preconceitos, do que deveria ser uma economia estável, que em avaliações empíricas sólidas (KRUGMAN, 2013; 2014, p.7).

\section{Uma avaliação da teoria do Banco Central Independente sob uma perspectiva pós-keynesiana}

Os defensores da independência do Banco Central tratam o tema como fundamental para o sucesso econômico dos países, em termos de crescimento e controle de inflação. No entanto, algumas correntes discordam da maneira como esse tema é tratado, propondo alternativamente que a política monetária e a atuação do $\mathrm{BC}$ devem ir além da estabilidade do nível de preços.

Como visto nas seções anteriores, a tese do BCI sustenta-se em pressupostos como os de neutralidade da moeda, existência de uma taxa natural de desemprego e ineficácia de política monetária discricionária. Tais pressupostos encontram forte oposição da escola pós-keynesiana, para a qual a política monetária possui papel determinante e não neutro, mesmo em longo prazo, e para a qual, portanto, a autoridade monetária é parte integral e extremamente relevante do sistema econômico e não um mero coadjuvante renegado a uma função auxiliar, (quase) perenemente não discricionária, com base em um pressuposto de taxa natural de desemprego, que essa corrente igualmente não compartilha.

\subsection{A política monetária}

A escola pós-keynesiana busca resgatar e utilizar ao máximo as ideias de Keynes e a estrutura teórica básica legada por ele e por seus principais seguidores. Dentre elas, o pressuposto de que a política monetária não é neutra e pode ser eficiente, tanto no curto como no longo prazo, estimulando a demanda agregada e agindo, assim, sobre renda e emprego. Para compreender o poder que a moeda detém no funcionamento da economia é preciso entender o seu papel na teoria pós-keynesiana, diametralmente oposto à visão convencional. 
Em Keynes, a moeda não é apenas um meio de troca, mas sim um ativo que influencia e é influenciado pelas decisões dos agentes. Afinal, se a única função da moeda fosse a de um meio que viabilizasse a troca de mercadorias entre produtor e consumidor, o sistema econômico contemporâneo não seria nada mais do que um mero escambo entre as partes (CARVALHO, 2005, p. 327). Logo, os agentes não estão inseridos em uma economia de trocas simples, mas sim em uma economia monetária, empresarial, composta por bancos, firmas e consumidores, além de governo e setor externo. Nessa economia, toda a produção visa ao lucro e o processo produtivo consiste em aplicar dinheiro para a obtenção de um montante maior no final do processo (KEYNES, 1971).

Assim, a moeda assume funções que vão além de meio de troca, como ser uma unidade de medida e reserva de valor (KEYNES, 1984). Os agentes têm ciência de que a moeda não possui rendimento próprio, mas que detém a máxima liquidez - o que lhe confere um rendimento implícito, em razão da flexibilidade proporcionada por essa liquidez - enquanto outros ativos podem oferecer rendimentos maiores, mas com flexibilidade menor e, muitas vezes, riscos superiores, em virtude dessa menor liquidez. Logo, a moeda, em certo sentido, é um ativo como outro qualquer, com seu rendimento total devendo ser medido também por intermédio da preferência pela liquidez, a qual se eleva, em épocas de maior incerteza (CARVALHO, 1996, p. 171).

Nesse cenário, a política monetária tem um papel crucial, dado que alterações na quantidade de moeda ou, mais propriamente, no preço (taxa de juros) dos empréstimos ocasionam modificações nos preços dos demais ativos, gerando mudanças na composição da riqueza dos agentes (MCLEAY et al., 2014a, p. 8; 2014b, p. 3). Assim, a política monetária não tem impacto exclusivamente, ou mesmo principalmente, sobre a variação dos meios de pagamento presentes no sistema econômico, mas, em virtude de alterações no "preço do dinheiro" conduz a modificações na composição dos ativos dos agentes, podendo resultar também em mudanças na produção e nas decisões de investimento dos empresários e, por conta disso, afetar as variáveis econômicas não só em curto como em longo prazo (CARVALHO, 2005. p. 327; LIBÂNIO, 2004, p. 9).

É em meio a esses fatores que a política monetária ganha argumentos sobre sua eficácia e impactos, também em longo prazo, por exemplo, pelas suas consequências sobre investimentos. Sicsú (1996a, p. 47) mostra que, sob uma concepção pós-keynesiana, o uso discricionário de instrumentos monetários não pode ser tratado como irresponsabilidade política. Pelo contrário, quanto maior a coordenação entre os instrumentos monetário, fiscal e cambial, maior seria a eficiência da economia vigente. Sicsú (1996b, p. 4) sintetiza que uma política econômica ideal e eficiente se ancoraria em três pontos substanciais:

1) Perseguir um objetivo prioritário; possuir um objetivo claro, impedindo ações conflitantes entre si, evitando perdas e tendo liberdade para agir além da estabilização dos preços. 
2) Criar o mínimo de contradição entre os instrumentos econômicos, evitando, por exemplo, que uma política monetária diminua a eficiência da política fiscal e vice-versa. Ou, caso contrário, permitir a instauração de um cenário de ineficácia e incerteza perante os demais agentes da economia.

3) Emissão do maior número de sinais sobre a condução da política econômica, o que é importante para que os agentes conheçam previamente, da melhor forma possível, os possíveis rumos da economia. Essa maior clareza se traduziria em uma menor necessidade de uso de instrumentos monetários e/ou fiscais e na redução da incerteza, ponto bastante enfatizado por Keynes (1981), em sua participação na Comissão Macmillan.

Os pontos levantados acima permitiriam, quando necessário, uma política monetária ativa. No entanto, deve-se enfatizar que, por coordenação entre política monetária e fiscal, entende-se uma relação de complementaridade e não de subordinação, na qual a política monetária não existe exclusivamente para legitimar a política fiscal e evitar "a impressão de moeda" e o aumento do nível dos preços, como na visão tradicional (WRAY, 1998). Cabe a essa política ter limites próprios, mas trabalhando de maneira conjunta com os instrumentos fiscais. Essa diferenciação é importante, pois, no caso de subordinação entre políticas, pode-se criar uma expectativa entre os agentes que os levaria a crer que o aumento do estoque monetário comprometeria a política fiscal, refletindo-se em um aumento do nível de preços e prejudicando não apenas a política monetária, mas todo o arranjo macroeconômico (CARVALHO, 1996, p.166).

O caso do Bank of England, na década de 1970, é um exemplo dos problemas oriundos da subordinação da política monetária à política fiscal. Além de reduzir a eficiência da atuação daquele Banco Central, uma grande parcela da política monetária se dedicava a assegurar as ações da política fiscal, colocando essa última em uma posição de força e a primeira como auxiliar. O sistema formatado dentro desses moldes teria, então, para muitos, acarretado um descontrole inflacionário na Grã-Bretanha naquele período (SICSÚ, 1996b, p. 4; CHICK, 1973, p. 12).

Outro problema que pode ser destacado em comparação com os novo-clássicos refere-se aos objetivos a serem alcançados por essa corrente no tocante à política monetária. A ideia central novo-clássica restringe-se basicamente, quanto à esse quesito, a uma ação estabilizadora de preços, por parte da autoridade monetária, a fim de que a economia permaneça em equilíbrio.

Porém, sob a perspectiva pós-keynesiana, dois problemas originam-se desse pressuposto. O primeiro é em relação a políticas estabilizadoras, isto é, nesse caso, anti-inflacionárias. Como a moeda na teoria pós-keynesiana possui efeitos reais, em curto e longo prazo, os objetivos da política monetária podem ir muito além da estabilização, incluindo efeitos também sobre o produto, emprego e renda (AMADO, 2000, p. 72; CARVALHO, 2005, p. 331). 
O segundo problema está ligado ao pressuposto de que a taxa corrente de desemprego deve-se igualar a uma pretensa taxa natural de desemprego. Para os pós-keynesianos, não existe um equilíbrio (único) nos moldes walrasianos, no qual a economia se ajustaria de acordo com certas condições. Ademais, para essa corrente, a existência de uma taxa natural de desemprego é considerada no mínimo questionável, quando não absurda (PAULA, 2004, p. 260).

\subsection{A crítica ao Banco Central Independente}

Como visto na primeira sessão deste trabalho, grande parcela dos teóricos que defendem a independência do Banco Central adotam a hipótese de que políticas discricionárias geram viés inflacionário, o qual se reflete em perdas sociais. No entanto, essas teorias, são baseadas em suposições acerca de taxas naturais. A abordagem pós-keynesiana descarta esse tipo de taxas naturais, pois não reconhece a existência de um ponto de equilíbrio estável sobre o qual a economia repousaria ${ }^{5} \mathrm{e}$ que serviria de parâmetro para as ações dos policy makers.

Ademais, como já foi adiantado, do ponto de vista pós-keynesiano, a não neutralidade da moeda implica que a condução da política monetária influencia variáveis reais da economia, como emprego, produto e renda, tanto em curto como em longo prazo. Logo, delegar ao Banco Central uma única função, como perseguir a estabilidade dos preços, não seria eficiente frente às consequências das políticas monetárias sobre outras variáveis. Vale dizer que, no mínimo, é necessário considerar os trade-offs entre estas diversas variáveis (inflação, emprego, crescimento, balanço de pagamentos, etc.), o que é verdadeiro também para autores mais críticos e sofisticados da corrente principal, como Svensson (2005, p. 19) ou mesmo Bernanke et al. (1999). Assim, para os pós-keynesianos, a política monetária deve ter como principal objetivo permitir o funcionamento de uma economia em pleno emprego, com orçamento e balanço de pagamentos sustentáveis, em prazos longos, e inflação moderada e estável, ou cadente (CARVALHO, 1996, p. 173).

A onipresença da incerteza reforçaria tal postura, dado que mudanças conjunturais, oscilações econômicas ou mesmo eventuais crises, inesperadas e impossíveis de prever acuradamente de forma probabilística - pelas próprias características não ergódicas da incerteza, em uma acepção pós-keynesiana (DAVIDSON, 2015, p. 16; DEQUECH, 2011, p. 623) - poderiam ser melhor combatidas e/ou atenuadas pela ação de uma equipe competente no comando do Banco Central, tendo boa compreensão de todas essas importantes características das economias, com seus respectivos trade-offs, e não apenas tendo em vista como meta oscilações no nível de preços (WRAY, 2014). Ademais, uma maior eficiência do Banco Central, dadas essas características das economias capitalistas, seria apenas atingida, segundo essa

\footnotetext{
Nem mesmo no tocante a variáveis específicas, como emprego, inflação, etc., as quais poderiam ter suas respectivas taxas "naturais" e/ou de equilíbrio.
} 
concepção teórica, por meio de uma ação coordenada entre Banco Central e Tesouro, isto é, em uma atuação em direção completamente oposta à postulada pelas teorias que baseiam a independência de Banco Central e da política monetária em relação às ações do Tesouro e da política fiscal (CARVALHO, 1996, p. 173; 2005, p. 329; WRAY, 2014, p. 13; LIBÂNIO, 2004, p. 13).

Wray (2014, p. 24) - em meio a muitos de seus escritos e de economistas a ele ligados - não cansa de apontar para a necessidade de coordenação, ademais, incontornável, entre Bancos Centrais e Tesouros, por exemplo, para o lançamento e a utilização de títulos públicos para a execução da política monetária e da política fiscal. De mais a mais, em meio a razões teóricas - explicadas em vários desses escritos, no que se chama atualmente de Moderna Teoria Monetária (MMT, em inglês) - historicamente, os Bancos Centrais surgiram como braços dos Tesouros e, portanto, dos governos e não como instituições independentes, e é assim, por meio dessa interação mais harmoniosa, como mostram esses autores, que essas instituições funcionam de forma mais eficiente e harmoniosa, como nos EUA.

Portanto, ao adotar uma política que consiste em alcançar exclusivamente a estabilidade do nível de preços, um BCI pode aumentar os custos que recaem sobre a sociedade, como perda de empregos, diminuição da produtividade e queda de salários (CARVALHO, 2005, p. 326; SVENSSON, 2005, p. 19). Ora, em uma democracia, a sociedade elege um representante para alcançar vários objetivos, sendo o controle da inflação apenas um deles. Logo, manter um Banco Central independente, que apenas encalça uma baixa inflação, sem se importar, ao menos mais fortemente, com outros objetivos, mostra-se claramente antidemocrático (FREITAS, 2006, p. 289; LEVY, 1995, p. 191).

Desse ponto de vista, o BCI e a democracia seriam compatíveis apenas diante do cumprimento de dois requisitos: a) a política monetária ter um efeito direcionado, afetando a estabilidade de preços e solidez do mercado financeiro, mas sem alterar fortemente o nível de emprego, a capacidade produtiva e a qualidade da vida da sociedade; b) o Banco Central possuir um método sistemático e objetivo para selecionar a política adequada que cumpra a meta de uma moeda estável e garanta a saúde do setor financeiro, sem optar por políticas erráticas (LEVY, 1995, p. 190).

Os dois requisitos teriam dificuldade em se fazerem cumprir. $\mathrm{O}$ primeiro insere-se no debate já apresentado sobre a neutralidade ou não da política monetária. No caso do pensamento novo-clássico, o pressuposto de neutralidade da moeda já cumpriria o primeiro requisito, enquanto para os pós-keynesianos, a política monetária possui impacto na condução da economia, tanto em curto como em longo prazo. A dificuldade do segundo requisito reside na preferência pela estabilidade de preços em detrimento de outros fatores. $\mathrm{O}$ Banco Central pode decidir zerar a inflação à custa de uma recessão, cumprindo a meta de estabilidade de preços e até mesmo alcançando certa higidez do setor financeiro ou acarretando alguns prejuízos a esse setor. Em suma, para os pós-keynesianos, os requisitos para a compatibilidade entre democracia e independência do Banco Central são improváveis de serem alcançados. 
Rymes (1995, p. 185-186) também destaca problemas para a compatibilidade entre um Banco Central independente e os limites democráticos. Afinal, a Autoridade Monetária deixaria de ser uma das responsáveis por administrar, por meio de suas políticas, a estabilidade dos preços, passando a ser a principal responsável por essa estabilidade, o que deveria ser função do Governo, tomado conjuntamente, o que inclui o papel do tesouro e das políticas fiscais. Assim, para Rymes (1995), o Governo deveria/poderia determinar metas quanto a variações dos preços e os objetivos de longo prazo, por haver sido eleito e, portanto, por ter recebido um mandato visando cumprir um determinado programa, enquanto o Banco Central ficaria responsável por parte dos meios para alcançar essas metas.

Os impactos causados pelas decisões da Autoridade Monetária não deveriam, assim, poder ser tratados fora de uma discussão que envolvesse a democracia e a política, sendo submetidos à aprovação de uma autoridade governamental e consequentemente ao público em geral. Numa visão contrastante, Shull (1995, p. 217) argumenta que a excessiva intervenção política também poderia ser danosa, gerando margem, tanto para que ocorresse uma contaminação dos objetivos da política monetária por políticas populistas quanto influências excessivas da autoridade monetária sobre (a tomada de decisões em) outras esferas políticas. Em ambos os casos, os princípios democráticos e a atividade do Banco Central poderiam deixar-se influenciar por interesses particulares de um pequeno grupo. Uma possível solução seria uma maior abertura para outros grupos de interesses serem representados nas decisões de política monetária, além do governo e de representantes do setor financeiro.

Crocco e Jayme Jr. (2003, p. 15-16) apontam que três ilusões foram criadas sobre a tese da independência do Banco Central, as quais gradualmente se provaram falsas, ou meia-verdades: (i) que um BCI contribuiria para a atração de capitais internacionais; (ii) que o governo não abriria mão de seu controle sobre a economia; $\mathrm{e}$ (iii) que a existência de um Banco Central independente diminuiria a taxa de juros.

A primeira dessas ilusões origina-se da ideia de que a presença de um Banco Central independente seria responsável pelo aumento do fluxo de reservas para o país que adota tal institucionalidade, pois os investidores estrangeiros a veriam como um sinal positivo, sentindo-se encorajados a investir nesse país. Porém, a busca dos investidores internacionais é pelo lucro que pode se obter em determinado país, o que não necessariamente está conectado a um determinado tipo de institucionalidade, incluindo a do Banco Central. Logo, se um país propiciar um cenário macroeconômico favorável (desfavorável) para os investidores, atrairá (repelirá) capitais para si, independentemente da institucionalidade em que sustenta sua condução monetária.

A segunda dessas ilusões é mais crítica, já que o problema central é decidir, nesse contexto de independência, a quem será atribuída a determinação da taxa de juros (se possível, em harmonia com outras políticas macroeconômicas), tão relevante para os diversos agentes e seus desempenhos (MENDONÇA, 2000, p. 49; CARVALHO, 2005, p. 327). Uma questão que emerge, então, é: como harmo- 
nizar essas várias políticas, se um dos entes por elas responsável é independente dos demais? Nesse mesmo sentido, caso o governo revisasse as decisões do Banco Central, em tal institucionalidade, por exemplo, em razão de insatisfações quanto à coordenação entre políticas, isso poderia levar à consequências desfavoráveis sobre a real independência do Banco Central, ainda que essa independência seja sempre muito limitada, para dizer o mínimo (WRAY, 2014, p. 26), exatamente pela importância da inter-relação das políticas monetárias com as fiscais, ou seja, do Banco Central com o Tesouro.

Por fim, a crença de que um Banco Central independente garantiria uma queda na taxa de juros também destoa da realidade. Enquanto a hipótese afirma que os investidores, ao perceberem credibilidade e segurança em um país, aceitariam taxas de juros menores, dado um menor risco, na prática essa assertiva desconsidera que muitos países, sobretudo os periféricos, adotam taxas de juros sistematicamente elevadas, na tentativa de evitar a fuga de/atrair capitais, permitindo assim manter sustentáveis seus Balanços de Pagamentos (FRITZ et al., 2014, p. 14).

Algumas dessas ilusões são oriundas de estudos empíricos que buscaram, a qualquer custo, mensurar e confirmar a eficiência da independência do Banco Central, relacionando essa suposta independência com o combate à inflação. Mesmo os índices de Cukierman, Webb e Neyapti (1992) que tentam captar o caráter qualitativo da condução da política monetária pelo $\mathrm{BC}$, carecem de completa objetividade. Mendonça (2000, p. 64) destaca, nesse mesmo sentido, que a maneira como perguntas foram formuladas, em tais pesquisas, condicionam os respondentes a revelar uma correlação negativa entre a maior independência do Banco Central e a inflação.

Sicsú (1996a, p. 46) também aponta que a relação entre grau de independência do Banco Central e taxas de inflação não é causal, já que países conhecidos por aversão à inflação terão construído uma forte institucionalidade direcionada para esses fins, ao contrário de países (mais) coniventes com a inflação. Bibow (2010, p. 26-27) destaca que uma das principais críticas novo-clássicas ao keynesianismo original era que esse supunha a existência de um governo que sempre se adequava aos interesses da sociedade e do crescimento econômico, uma espécie de "ditador benevolente", alheio a interesses políticos. A proposta do BCI, por sua vez, tenderia a se aproximar de uma figura neutra que operaria visando o bem maior, mas dessa vez não como um governo, mas como uma autoridade monetária que não tem que prestar contas à sociedade e, assim, pode ser mais objetivo e racional. Bibow defende, fugindo dessa dicotomia simplista, que a discussão do desenho institucional e das limitações da política monetária é mais importante do que a pura discussão sobre a independência do Banco Central, que para ele tem mais relação com o avanço político de ideias neoliberais durante o fim da década de 1980 do que com evidências claras de sua eficiência numa realidade democrática.

Em suma, a tentativa de provar a maior eficiência dos Bancos Centrais independentes parte de pressupostos que desconsideram os arranjos produtivos e 
institucionais prévios a essa institucionalidade específica, desdenhando também, ademais, dos ônus de tal arranjo e pretensão de independência, dada a inevitável interdependência e coordenação entre Bancos Centrais e Tesouros, vale dizer, entre política monetária e fiscal, como tantas vezes foi aqui assinalado (WRAY, 2014, p. 28). É exatamente por isso que De Paula (2004, p. 257) aponta que a presença de um BCI na economia pode gerar descoordenação entre políticas, causando impactos negativos sobre investimentos, dívida pública e inadimplência.

\section{Conclusões}

O presente artigo tratou da relação entre estabilidade de preços e independência do Banco Central. A teoria convencional propõe uma condução da política monetária livre de influências externas, sendo seus argumentos balizados em uma série de modelos e pressupostos que se apoiam em uma pretensa neutralidade da moeda, na presença de uma igualmente suposta taxa natural de desemprego e consequentemente na existência de um viés inflacionário, caso os responsáveis pelas políticas econômicas desconsiderem esses parâmetros.

É inegável a maneira como essa teoria se espraiou pelos círculos acadêmicos e não acadêmicos, como um bastião para a higidez macroeconômica dos países, buscando se atualizar, por seus melhores e mais críticos autores, como Svensson, por meio de novos pressupostos e gerações de modelos.

Ao contrapor esse arcabouço com os de outras correntes, como os da chamada corrente pós-keynesiana, foi mostrado algumas debilidades cruciais dessas ideias de uma política monetária exclusivamente estabilizadora, com base em um BCI, como por exemplo, a necessária e incontornável coordenação entre Bancos Centrais e Tesouros, quando, entre outras ações, do lançamento e utilização de títulos públicos para a execução tanto de políticas monetárias como fiscais (WRAY, 2014). Adicionalmente, a crítica aos pressupostos de não neutralidade da moeda $\mathrm{e}$ de existência de certas taxas "naturais" como a de emprego, de crescimento econômico de longo prazo, etc., coloca mais dúvidas sobre a adequação teórica e empírica dessa teoria convencional acerca da condução da política monetária e de construção de instituições a ela ligadas.

\section{Referências}

ALESINA, A; SUMMERS, L. Central Bank Independence and Macroeconomic Performance: Some Comparative Evidence, Journal of Money, Credit and Banking, 1993. crossref https://doi.org/10.2307/2077833

AMADO, A. M. Limites monetários ao crescimento: Keynes e a não-neutralidade da moeda. Ensaios FEE, v. 21, n. 1, p. 44-81, 2000. 
BARRO, R. J.; GORDON, D. Rules, Discretion and Reputation in a Model of Monetary Policy. Journal of Monetary Economics, 12, , North-Holland. 1983.

BERNANKE, B.S.; LAUBACH, T.; MISHKIN, F.S.; POSEN, A.S. Inflation Targeting: Lessons from the International Experience. Princeton: Princeton University Press, 1999.

BIBOW, J. A Post Keynesian Perspective on the Rise of Central Bank Independence: a dubious succes story in monetary economics. Jerome Levy Economics Institute Working Paper, n. 625, p. 1-33, 2010.

BULLIO, O. M. B.; RAIMUNDO, L. DE C. Independência do Banco Central: uma leitura crítica de sua sustentação teóricaI Encontro Internacional da Associação Keynesiana Brasileira.2008

CARVALHO, F. J. C. The independence of central banks: a critical assessment of the arguments. Journal of Post Keynesian Economics, v. 18, n. 2, p. 159-175, 1996.

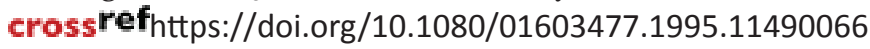

et al. Economia Monetária e Financeira: Teoria e Política. $2^{a}$ Ed. Rio de Janeiro. Elsevier, 2007.

- Uma contribuição ao debate em torno da eficácia da política monetária e algumas implicações para o caso do Brasil. Revista de Economia Política, v. 25, n. 4 (100), p. 323-336, 2005.

CHICK, V.. The Theory of Monetary Policy. Oxford: Blackwell. 1973.

CROCCO, M.; JAYME JR., F. G. Independência e autonomia do Banco Central: mais sobre o debate. Textos para discussão, n. 199, p. 1-17, 2003.

CUKIERMAN, A.; WEBB, S.; NEYAPTI, B. Measuring the Independence of Central Banks and Its Effects on Policy Outcomes. World Bank Economic Review, 6(3), 1992. crossrefhttps://doi.org/10.1093/wber/6.3.353

DAVIDSON, P. A rejoinder to O'Donnell's critique of the ergodic/nonergodic explanation of Keynes's concept of uncertainty. Journal of Post-Keynesian Economics, v. 38, n. 1, p. 1-18. 2015. crossrefhttps://doi.org/10.1080/ 01603477.2015.1078701

DEQUECH, D.. Uncertainty: a typology and refinements of existing concepts. Journal of Economic Issues, v. 45, n. 3, p. 621-640, 2011. crossref https://doi. org/10.2753/JEI0021-3624450306 
FREITAS, M. C. P. DE. Banco Central Independente e coordenação das políticas macroeconômicas : lições para o Brasil. Economia e Sociedade, v. 15, n. 1, p. 269-293, 2006.

FRITZ, B; PRATES, D M.; de PAULA, L. F. (2014) Keynes at the Periphery: Currency Hierarchy and Challenges for Economic Policy in Emerging Economies. XLII Encontro Nacional de Economia (Associação Nacional dos Centros de Pós-Graduação em Economia - ANPEC). Natal: Mimeo.

KEYNES, J. M. A Teoria geral do Emprego (1937). In SZMRECSANYI, Tamás (Org.) John Maynard Keynes: Economia. $2^{a}$ ed. São Paulo: Atica, p. 167-179, 1984.

. A tract on Monetary Reform. The Collected Writings of John Maynard Keynes, v. 4, Londres: Macmillan, 1971.

. Activities 1929-1931: rethinking employment and unemployment policies. In: MOGGRIDGE, D (Org.) The Collected Writings of John Maynard Keynes. v.20, Londres: Macmillan, 1981.

KYDLAND, F. E.; C.PRESCOTT, E. Rules Rather than Dicertion: The Incosistency of Optimal Plans. The Journal of Political Economy, v. 85, n. 3, p. 473-491,

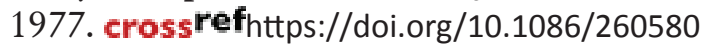

KRUGMAN, P. The four percent solution. The Conscience of a Liberal. (http:// krugman.blogs.nytimes.com/2013/05/24/the-four-percent-solution/);2013. Acesso em: 27 de Abril de 2016.

. Inflation Targets Reconsidered. Draft Paper for ECB Sintra Conference, May.2014.

LEVY, A.D. Does an independent central bank violates democracy? Journal of Post Keynesian Economics, v. 18, n. 2, p. 189-210, 1996. crossref https://doi.org/10 $.1080 / 01603477.1995 .11490068$

LIBÂNIO, G. A. Temas de Política Monetária: uma perspectiva pós-keynesiana. Texto para discussão, n. 229, p. 1-22, 2004.

MCLEAY, M; RADIA, A; THOMAS, R. Money in the modern economy: an introduction. Bank of England Quarterly Bulletin, v. 54, n. 1, p. 4-13. 2014;

. "Money creation in the modern economy". Bank of England Quarterly Bulletin, v. 54, n. 1, p. 14-27. 2014. 
MENDONÇA, H. F. DE. Independência do Banco Central, Âncoras Nominais e Coordenação de Políticas: Uma Análise de Diversos Mecanismos de Estabilização. UFRJ, 2001.

. Mensurando a Credibilidade do Regime de Metas Inflacionárias no Brasil. Revista de Economia Política, v. 24, n. 3, p. 344-350, 2004.

. A teoria da independência do banco central: uma interpretação crítica. Estudos Econômicos, São Paulo, v. 30, n. 1, p. 101-127 . 2000.

MODENESI, A.M . Regimes Monetários: teoria e experiência do Real. São Paulo. Manole, 2005.

PAULA, L. F. R. DE. A questão da autonomia do banco central: uma visão alternativa. Indicadores Econômicos FEE, v. 32, n. 1, p. 253-263, 2004.

RYMES, T. K. autonomous and accountable. Journal of Post Keynesian Economics, v. 18, n. 2, p. 177-188, 1996. crossrefhttps://doi.org/10.1080/01603477. 1995. 11490067

ROGOFF, K. The Optimal Degree of Commitment to an Intermediate Monetary Target. The Quarterly Journal of Economics, November 1985. cross ref https://doi.org/10.2307/1885679

SARGENT, T.; WALLACE, N. "Rational" Expectations, the Optimal Monetary Instrument, and the Optimal Money Supply Rule. Journal of Political Economy, vol. 83 , n. 2, p. 241-54, 1975. cross ref https://doi.org/10.1086/260321

SHULL, B. Federal Reserve independence: what kind and how much? Journal of Post Keynesian Economics, v. 18, n. 2, p. 211-230, 1996. crossrefhttps://doi.org/ 10.1080/01603477.1995.11490069

SICSÚ, J. A tese da independência do Banco Central e a estabilidade de preços: uma aplicaçao do método Cukierman à história do FED. Estudos Econômicos, v. 26, n. 1, p. 21-49, 1996a.

. Uma Crítica à Tese da Independência do Banco Central. Nova Economia, v. 5, n. 2, p. 10, 1996 b.

SVENSSON, L.O. Further Developments of Inflation Targeting. Prepared for "Inflation Targeting: Implementation, Communication and Effectiveness". Workshop at Sveriges Riksbank, Stockholm, June 10-12, 2005. 
. Optimal Inflation Targets, Conservative Central Banks, and Linear Inflation Contracts. American Economic Review. V. 87. n. 1. 1997.

VERCELLI, A. Methodological foundation of macroeconomics: Keynes and Lucas. Cambridge, Cambridge University Press, 1991. crossrefhttps://doi.org/ 10.1017/CBO9780511896217

WALSH, C. Optimal Contracts for Central Bankers. The American Economic Review, 85. 1995.

WRAY, L. R. Central Bank Independence: Myth and Misunderstanding. Levy Economics Institute of Bard College Working Paper, n. 791, 2014.

. Understanding Modern Money: The Key to Full Employment and Price Stability. Cheltenham: Edward Elgar, 1998.

Recebido em 26.05.16

Aprovado em 14.12.16 